\title{
Thermal compact modeling for power electronic devices in D2Pak enclosures
}

by M. Lis, B. Wiecek, T. Wajman

Computer Thermography Group, Institute of Electronics,

Technical University of Lodz, Poland

e-mail: foxm@thermo.p.lodz.pl, wiecek@ck-sg.p.lodz.pl, twajman@thermo.p.lodz.pl

\section{Abstract}

In this paper, the compact modeling of power electronic devices is presented. Physical modeling using ANSYS is helpful to identify the compact model parameters. Thermographic measurements were applied to modeling validation. Compact models are very easy for computation, so they generate the results fast and with satisfactory accuracy.

\section{Introduction}

Thermal physical modeling using finite difference or finite element methods can be sometimes very complex and time consuming while computation. It is mainly because of thousands of nodes where the differential equations have to be fulfilled.

The different approach for thermal modeling assumes a very low number of boundary nodes, and one where the power is generated [3-5]. There is a heat transfer in between all nodes. It is necessary to know what is the portion of total power which is transferred to the ambient through each boundary node. Such modeling is known as compact modeling, and it is simple, and fast for computations. It can be quite helpful for engineering as well as for manufacturers of heat sources, because its precision is good enough and can be trimmed according the problem being solved.

In this paper we present compact modeling for power electronic devices encapsulated in D2Pak cases. It is well known fact that thermal and electrical quantities analogy (Table 1) allows to use electrical and electronic simulation packages in thermodynamics. Compact modeling is one the best example for using electronic solvers for thermal problems.

Table 1: Thermal to electrical quantities conversion [1]

\begin{tabular}{|l|c|l|}
\hline Power $\mathrm{P}[\mathrm{W}]$ & $\Rightarrow$ & Current $\mathrm{J}[\mathrm{A}]$ \\
\hline Temperature $\mathrm{T}[\mathrm{K}]$ & $\Rightarrow$ & Voltage $\mathrm{U}[\mathrm{V}]$ \\
\hline Thermal resistance $\mathrm{R}_{\mathrm{TH}}[\mathrm{K} / \mathrm{W}]$ & $\Rightarrow$ & Electrical resistance. $\mathrm{R}[\Omega]$ \\
\hline Thermal capacitance $\mathrm{C}_{\mathrm{TH}}[\mathrm{J} / \mathrm{K}]$ & $\Rightarrow$ & Electrical capacitance. $\mathrm{C}[\mathrm{F}]$ \\
\hline Thermal conductivity $\lambda[\mathrm{W} /(\mathrm{m} \cdot \mathrm{K})]$ & $\Rightarrow$ & Electrical conductivity $\sigma[\mathrm{S} / \mathrm{m}]$ \\
\hline
\end{tabular}

\section{Compact model for steady state}

Compact models are derived from classical energy equation

$$
\frac{\partial}{\partial x}\left(\lambda \frac{\partial T}{\partial x}\right)+\frac{\partial}{\partial y}\left(\lambda \frac{\partial T}{\partial y}\right)+\frac{\partial}{\partial z}\left(\lambda \frac{\partial T}{\partial z}\right)=-p_{v}
$$

where: $T$ - temperature, $p_{v}$ - volumetric power density, $\lambda$ - thermal conductivity.

Compact modeling as a simplified solution for heat transfer in solid bodies needs the following assumptions: 
a) the heat source is inside the solid body

b) the boundary of the body is segmented into the $\mathrm{n}$ parts with constant temperature $T_{i}(i=1, \ldots, n)$.

It is possible to prove [3,4], that if the eqn. (1) is linear, i.e.: $\lambda$ does not depend on temperature, the temperature in heat source $T_{j}$ is the linear combination of $T_{i}(i=1, \ldots, n)$, Additionally, temperature $T_{j}$ is a function of power dissipated $\mathrm{P}$, as expressed by:

$$
T_{j}=R_{t h J 0} \cdot P+\sum_{i=1}^{n} a_{i} T_{i}
$$

where: $R_{\text {th } J 0}, a_{i}-$ model parameters,

$P=\int_{v} P_{v} d v$ - power dissipated in the heat source with volume $v$

Assuming constant boundary temperature $T_{0}=T_{i}=$ const, and if the same heat flux is transferred through all part of the boundary, we can obtain additional equation, which has to be fulfilled:

$$
\sum_{i=1}^{n} a_{i}=1
$$

As a consequence, eqn. (2) is reduced to a form:

$$
T j=R_{\text {thJo }} \cdot P+T_{\text {o }}
$$

By assuming constant boundary temperature $T_{0}$, we can easily identify the first model's parameter $R_{\text {th } J \text { o. }}$ In practice, the heat transfer from the heat source to the ambient is much more complex, due to complex geometry of the investigated body and different boundary conditions. Temperature in this model is understood as the temperature difference between a given point and the ambient.

For the model completeness, one has to know how much power is dissipated to the ambient through the certain areas of the investigated heat source. We define the coefficients $q_{k}$ describing the portions of power $J_{k}$ transferred out of the surface in the $k$-th node. The temperature in the boundary nodes $T_{i}$, for $i=0,1, \ldots, n$, are different, are therefore there is a heat flux in between. Such a flux in between $i$-th and $k$-th nodes is presented in the model by additional parameters $R_{i, k}$, which can be treated as the thermal resistance between given points.

Power transferred from $i$-th node to $k$-th one, if $T_{k}=0$ takes a form:

$$
J_{i, k}=T_{i} / R_{i, k}
$$

Obviously, the similar power is transferred in opposite direction, depending on $T_{k}$, and therefore $R_{i, k}=-R_{k, i}$. Finally, the energy conservation in $k$-th node allows to find the part of power $J_{k}$ in this node dissipated to the ambient, as:

$$
J_{k}=P \cdot q_{k}+\sum_{i=1}^{n} \frac{T_{i}}{R_{i, k}}
$$

If the boundary temperature is constant, and $T_{i}=0$ in all nodes $(i=0,1, \ldots, n)$, we can get the next normalization condition for $q_{k}$ as below:

$$
\sum_{i=1}^{n} q_{i}=1
$$

Equations (2-7) describe a compact model [3-4] with $R_{t h\lrcorner o}, a_{i}, q_{k}, R_{i, k}$ parameters. Because of the model symmetry, and additional normalization conditions, eqn. (3) and (5), the total number of $(n+1)^{2}$ model parameters is reduced to fully independent ones, given by [3-4]

$$
\frac{1}{2}(n-1) \cdot(n+4)+1
$$

where $n$ is the number of boundary nodes of the heat source. 
As an example of applying compact modeling to power electronics, we present in this paper model of D2Pak enclosure (Fig. 1). Four boundary nodes were defined in the structure, i.e., metal pins $\left(n_{1}\right)$, top of the ceramic case $\left(n_{o b}\right)$, metal base $\left(n_{2}\right)$ mounted on the PCB (Printed Circuit Board), and the bottom of PCB $\left(n_{p d}\right)$. Silicon chip inside is the point where the power is generated.

A corresponding compact model in the form of a network is shown in Fig. 2.

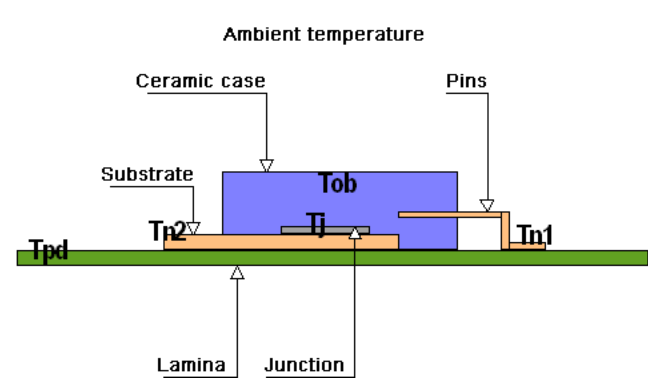

Fig. 1. D2Pak enclosure of power device with indicated nodes for compact model

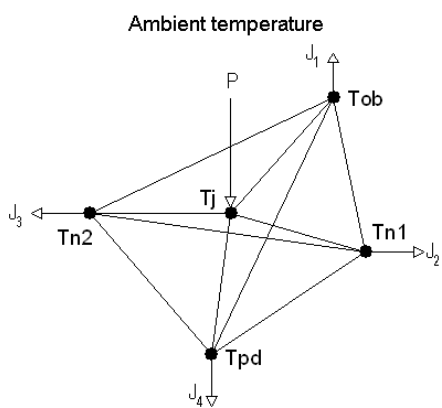

Fig. 2. Compact model of D2Pak, $T_{o b}$ - case temperature, $T_{n 1}$ - electrodes temperature, $T_{n 2}-$ metal radiator temperature, $T_{p d}-P C B$ temperature, $T j$ - junction temperature

\section{ANSYS simulations}

Compact modeling in our work was supported by physical simulations. It is done mainly to determine the portion of power transferred through all nodes to the ambient. It is more explained in sections 4-5 in this paper.

The model is for MOSFET (Metal-Oxide-Semiconductor Field Effect Transistor) power transistor in D2Pak ceramic case. The model is built up using the manufacturer's data presented in Table 2.

Table 2.Material parameters of modeled device

\begin{tabular}{|c|c|c|c|}
\hline & $\begin{array}{c}\text { Density } \\
{\left[\mathrm{kg} / \mathrm{m}^{3}\right]}\end{array}$ & $\begin{array}{c}\text { Specific heat } \\
{[\mathrm{J} /(\mathrm{kg} \cdot \mathrm{K})]}\end{array}$ & $\begin{array}{c}\text { Thermal conductivity } \\
{[\mathrm{W} /(\mathrm{m} \cdot \mathrm{K})]}\end{array}$ \\
\hline Cooper pins & 8960 & 385 & 386 \\
\hline Silicon heat source & 2330 & 710 & 150 \\
\hline Ceramic case & 4000 & 300 & 20 \\
\hline PCB & 2500 & 1000 & 5 \\
\hline Power generated in the source & \multicolumn{3}{|c|}{$0.75-1.5 \mathrm{~W}$} \\
\hline Ambient temperature & \multicolumn{3}{|c|}{$298.15 \mathrm{~K}$} \\
\hline Heat transfer coefficients & $2-5 \mathrm{~W} /\left(\mathrm{m}^{2} \cdot \mathrm{K}\right)$ (depending on the node) \\
\hline
\end{tabular}

A mesh for finite element modeling using ANSYS5.7, and the exemplary results are presented in Fig. 3.

Temperature distribution in Fig. 3 is obtained for total power of $1.5 \mathrm{~W}$ generated in the structure, what is corresponding to uniform power density of $2.45^{*} 10^{8} \mathrm{~W} / \mathrm{m}^{3}$ in silicon. Temperature of $416.9 \mathrm{~K}$ is on the top of the D2Pak case, while the maximum one in the junction is $421.6 \mathrm{~K}$. 


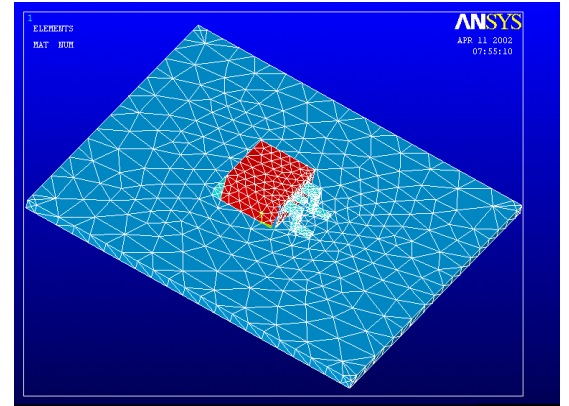

(a)

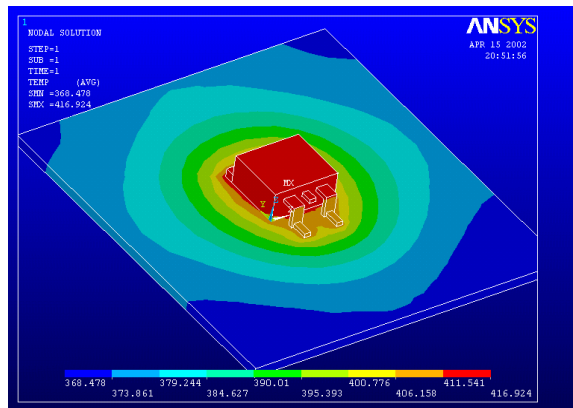

(b)

Fig. 3. Mesh for D2Pak enclosure (a), and temperature distribution (b), ANSYS5.7 modeling

\section{Compact model for D2Pak power device}

The physical model in ANSYS is defined for getting average temperature on subsurfaces corresponding to considered points of the structure $T_{n 1}, T_{n 2}, T_{p d}, T_{o b}$. Additionally, simulation provides portions of power $J_{1} \ldots J_{4}$ transferred to the ambient through the nodes. By solving linear equations (6) thermal resistances $R_{t h J o,} R_{i, k}$ as well as parameters $a_{i}, q_{k}$ are obtained for a given total power $P=0.75,1,1.25$ and $1.5 \mathrm{~W}$. Results are in table 3.

In order to validate the compact model, the results' comparison from both physical and compact modeling for different power $P=0.6,0.85,1.1,1.4,1.75 \mathrm{~W}$ are performed. Temperature $T_{n 1}, T_{n 2}, T_{p d}, T_{o b}$ and $T_{j}$ are calculated for comparison as shown in Table 4 , while their uncertainty are in Table 5.

Table 3. Parameters of compact model obtained using data from physical simulation

\begin{tabular}{|c|c|c|c|}
\hline$R_{\text {thjo }}$ & 7,6356 & $\mathrm{R}_{\mathrm{Tn2}-\mathrm{Tpd}}$ & $1,06 \mathrm{E}+1$ \\
\hline$a_{\mathrm{Tn} 2}$ & 1,667 & $\mathrm{R}_{\text {Tn2-Tob }}$ & $-5,43$ \\
\hline$a_{\mathrm{Tn} 1}$ & -1 & $\mathrm{R}_{\mathrm{Tn} 1-\mathrm{Tpd}}$ & $-8,85$ \\
\hline$a_{T p d}$ & $5.55 \mathrm{E}-1$ & $R_{\text {Tn1-Tob }}$ & $9,94 \mathrm{E}+1$ \\
\hline$a_{\text {Tob }}$ & $-2,22 \mathrm{E}-1$ & $\mathrm{R}_{\text {Tpd-Tob }}$ & $9,53 \mathrm{E}+1$ \\
\hline $\mathrm{q}_{\mathrm{Tn} 2}$ & $6,77 \mathrm{E}-2$ & & \\
\hline $\mathrm{q}_{\mathrm{Tn} 1}$ & $7,36 \mathrm{E}-1$ & & \\
\hline$q_{T p d}$ & $-2,6 \mathrm{E}-2$ & & \\
\hline $\mathrm{q}_{\mathrm{Tob}}$ & $2,22 \mathrm{E}-1$ & & \\
\hline$R_{T n 1-T n 2}$ & $-1,719$ & & \\
\hline
\end{tabular}

Table 4. Junction temperature obtained by physical and compact modeling, ANS - ANSYS5.7, Compact - Compact thermal model

\begin{tabular}{|c|c|c|c|c|c|c|c|}
\hline $\mathrm{P}$ & {$[\mathrm{W}]$} & 0,6 & 0,85 & 1,1 & 1,4 & 1,75 & \\
\cline { 1 - 7 } $\mathrm{T}_{\mathrm{j}}$-ANS & \multirow{2}{*}[\mathrm{K}]{} & 345,8 & 365,6 & 385,7 & 409,3 & 437,1 & \multirow{2}{*}{ Fig. 5a } \\
\cline { 1 - 6 } $\mathrm{T}_{\mathrm{j} \text {-Compact }}$ & & 346,5 & 368,5 & 388,1 & 412,6 & 441,5 & \\
\hline
\end{tabular}

Table 5. Uncertainty of junction temperature $T_{j}$

\begin{tabular}{|c|c|c|c|c|c|}
\hline $\mathrm{P}[\mathrm{W}]$ & 0,6 & 0,85 & 1,1 & 1,4 & 1,75 \\
\hline$\sigma[\%]$ & 1,5 & 4,3 & 2,7 & 3,0 & 3,2 \\
\hline
\end{tabular}


The measurement uncertainty is at the reasonable level for engineering practice, and the fast calculation is the main advantage of using compact modeling. It is possible to get junction temperature for different power generated in the device as well as for various boundary conditions, i.e.: different values of heat transfer coefficients.

\section{Thermographic measurements}

D2Pak device is a SMD (Surface Mounted Device) one. The metal pad below the component, where the element is soldered, contributes in cooling down the structure and can improve the heat transfer to the ambient. It acts as thermal spreader. The first modeling assume the different areas of the metal pad below the component. The maximum temperature of the junction is calculated. As shown below (Fig. 4), there is an improvement of device cooling, however after enlarging the pad's area above $50 \%$ of the component's area itself, the cooling down improvement is very small.

In order to verify the correctness of compact and physical modeling, thermographic measurements were performed. N-channel MOSFET power transistor were placed on the copper pad, which area was greater than the base of the component by $10 \%$. Table 6 contains the results from ANSYS simulations and measurements.
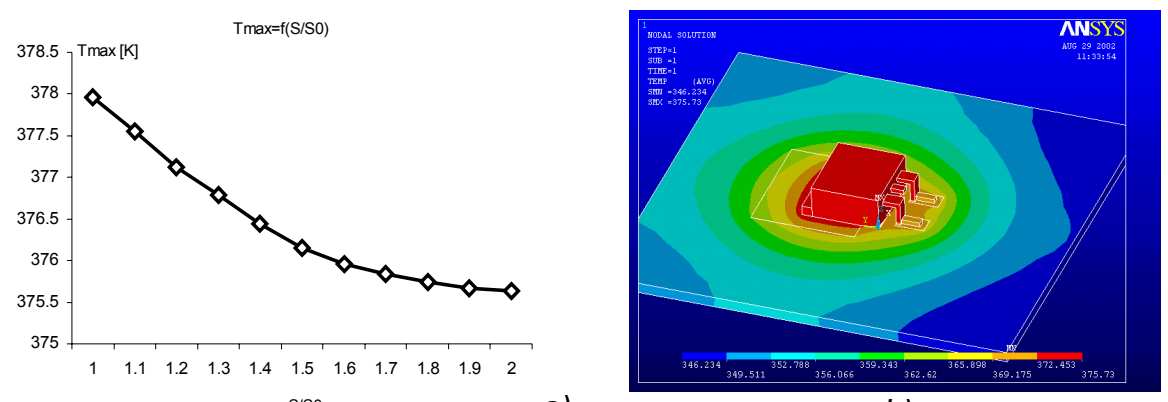

a)

b)

Fig. 4. Maximum temperature versus $\mathrm{S} / \mathrm{SO}, \mathrm{S}-$ area of pad, SO - area of metal base of the component

Additionally, the results from simulation and measurement are presented in Fig. 5, and chosen thermal images are in Fig. 6. For higher power, the characteristics obtained by measurements and simulation differ from each other. Heat transfer coefficients for upper and lower parts of the structure were chosen according the literature recommendations. The cooling conditions in the experiments were different in simulations and measurements. It is possible to match both results by choosing the proper heat transfer coefficients. Such an approach needs to use the optimization procedure.

Table 6. Maximum and minimum temperature - ANSYS simulations and measurements

\begin{tabular}{|c|c|c|c|c|}
\hline \multicolumn{5}{|c|}{ Results from ANSYS } \\
\hline $\mathrm{P}[\mathrm{W}]$ & 0,75 & 1 & 1,5 & 2 \\
\hline $\mathrm{T}_{\max }[\mathrm{K}]$ & 358,4 & 377,9 & 416,9 & 455,9 \\
\hline $\mathrm{T}_{\min }[\mathrm{K}]$ & 358,2 & 377,5 & 416,3 & 455,1 \\
\hline \multicolumn{5}{|c|}{ Results from thermal camera measurements } \\
\hline $\mathrm{P}[\mathrm{W}]$ & 0,7803 & 1,08 & 1,5123 & 1,92 \\
\hline $\mathrm{T}_{\max }[\mathrm{K}]$ & 356,5 & 373,4 & 396,1 & 423,1 \\
\hline $\mathrm{T}_{\min }[\mathrm{K}]$ & 332,4 & 349,7 & 370,1 & 385,1 \\
\hline
\end{tabular}




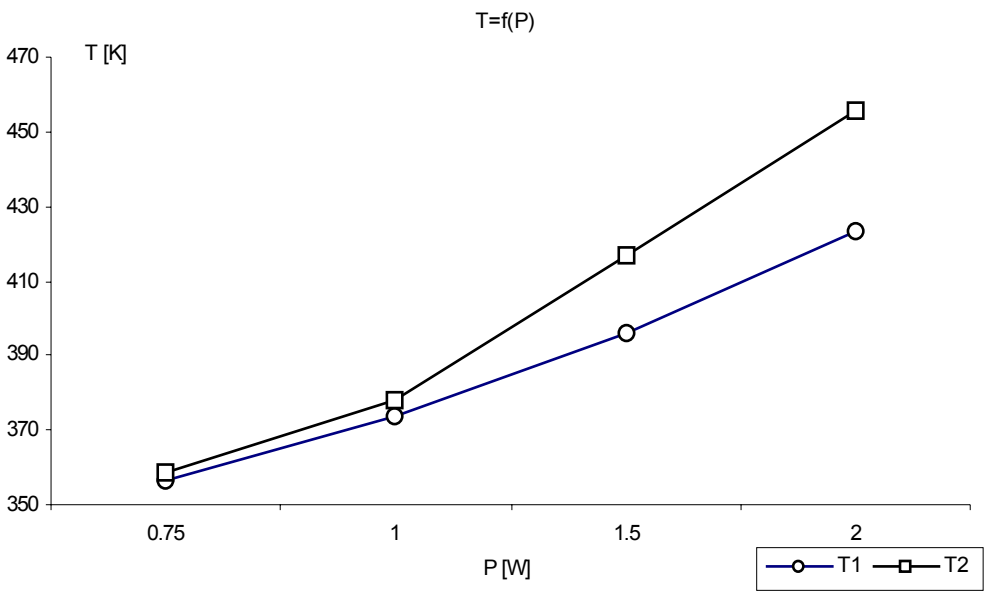

Fig. 5. Maximum temperature obtained by ANSYS simulations (T2) and thermographic measurements (T1)
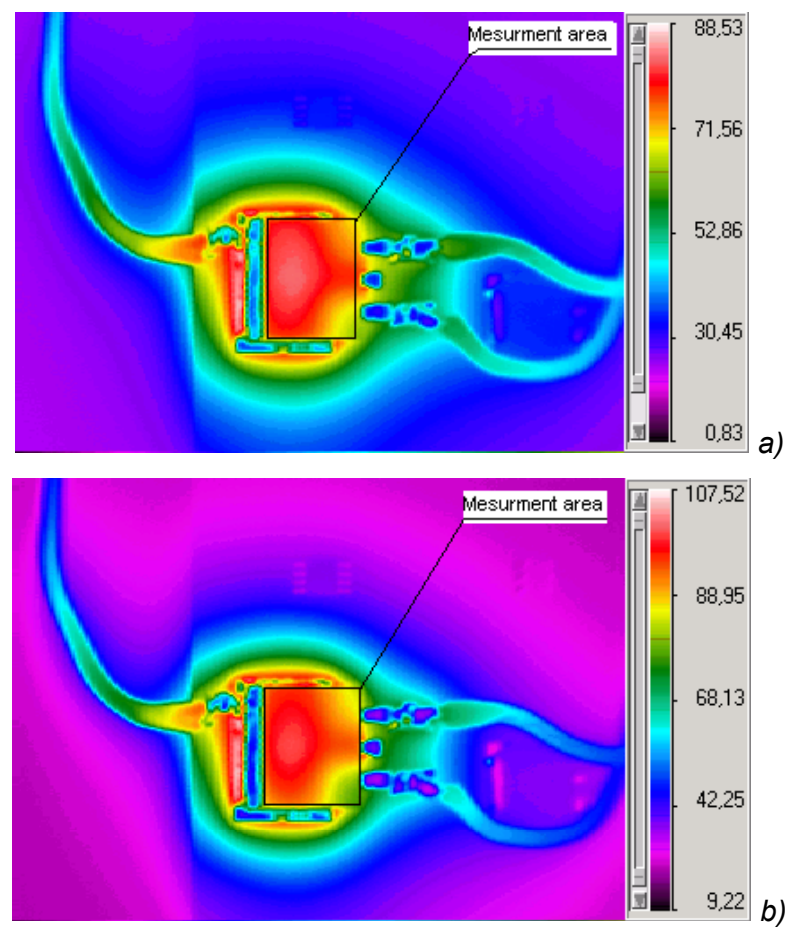

Fig. 6. Temperature distributions, a) $P=0.78 \mathrm{~W}, T_{\max }=356.5 \mathrm{~K}$, b) $P=1.08 \mathrm{~W}, T_{\max }=373.5 \mathrm{~K}$ 


\section{Conclusions}

Compact model of power electronic device in D2Pak is presented in this work. It has been shown that from physical modeling using advanced simulation software it is possible to find the portions of total power dissipated to the ambient through all nodes. These parameters are responsible for boundary conditions and are necessary for calculations model parameters. Thermography measurements have been used for verifying the model correctness.

Additionally, the influence of the area of metal pad on PCB under the power device in power dissipation to the ambient and cooling down the whole structure has been taken into account. It was proved by simulation, that the area above $50 \%$ of the device area do not improve cooling significantly.

Compact modeling is the powerful engineering tool for fast and acceptable calculations. Accuracy of such modeling can be improved by increasing number of boundary nodes, and thermography measurements. The problem of boundary conditions are solved either by physical simulation or by thermal measurements.

\section{REFERENCES}

[1] HERING M. - Termokinetyka dla elektryków, WNT, Warszawa 1980, in Polish

[2] WIŚNIEWSKI S. - Wymiana ciepła, PWN, Warszawa 1979, in Polish

[3] GERSTENMAIER Y. C. and WACHUTKA G. - Rigorous Model and Network for Transient Thermal Problems. $7^{\text {th }}$ THERMINIC Workshop, 24-27 September 2001, Paris, pp. 5-10

[4] GERSTENMAIER Y. C., PAPE H. and WACHUTKA G. - Rigorous Model and Network for Static Thermal Problems. $7^{\text {th }}$ THERMINIC Workshop, 24-27 September 2001, Paris, pp. 203-208

[5] BOSCH E. G. T. - Thermal Compact Models: An alternative approach. $7^{\text {th }}$ THERMINIC Workshop, 24-27 September 2001, Paris, pp. 191-196

[6] E. DRIESENS, S. Van DOOREN- Parametric Compact Models for the 72-pins Polymer Stud Grid Array ${ }^{T M}$. $6^{\text {th }}$ THERMINIC Workshop, 24-27 September 2000, Budapest, pp. 205-210 